\title{
The Challenges of Quantifying the Risk of Serious Infection with Tumor Necrosis Factor Antagonist Therapy
}

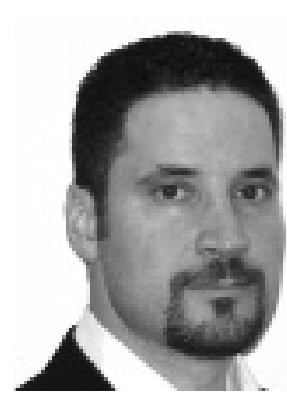

As early as 1725 the medical literature contained reports that certain acute bacterial infections coincided with cancer regression. This observation led some clinicians to intentionally infect their patients in the hopes of treating their cancer. While this approach was successful, it had the obvious risks of serious infection. In the late 1800 s the prominent American orthopedic oncologist William B. Coley hypothesized that it was the immune system's response to the bacterial infection and not the bacteria that was responsible for the beneficial tumor effect. Coley successfully experimented with a concoction of inactivated Serratia marcescens and Streptococcus pyogenes to treat inoperable sarcomas ${ }^{1}$. These experiments initiated the modern era of immunotherapy (the treatment of disease via the manipulation of immune response).

Almost 100 years later in 1975, Carswell, et al described a substance toxic to sarcoma cells that was released by macrophages in response to polysaccharide ${ }^{2}$. They later characterized the substance as a glycoprotein, which they named tumor necrosis factor (TNF). It is postulated that the lipopolysaccharide content of Coley's concoction may have stimulated the production of TNF by macrophages that resulted in sarcoma regression. Today, recombinant forms of TNF are used as an adjunct to surgery for certain sarcomas.

In addition to its direct cytotoxic effect on tumor cells, decades of research show TNF to be a multifunctional cytokine with antiviral activity and roles in the regulation of autoimmunity, inflammation, cardiac function, bone metabolism, control and containment of intracellular pathogens, and host response to infection and sepsis.

Given TNF's protective role in host defenses, the early clinical investigations of TNF antagonists anticipated increased serious infection rates. However, the first clinical trials evaluating the safety of TNF antagonists in rheumatoid arthritis (RA) performed in the mid to late 1990s did not note increased infection risk with TNF antagonist thera$\mathrm{py}^{3-5}$. While the initial results were comforting, the relative- ly small size of these early trials prohibited a definitive quantification of the risk of serious infection.

Similar to early-phase trials, registration trials for the first TNF antagonists did not show an increased risk of infection, and by the late 1990s, risk of serious infection with TNF antagonists did not seem overly problematic. In fact, the initial infliximab phase III study (ATTRACT) had an incidence of serious infections of $6 \%$ for placebo versus $1 \%$ for the recommended dose $^{6}$; the etanercept study did not report serious infections, and the total infection rate in the placebo group was $61 \%$ versus $53 \%$ in the active group ${ }^{5}$.

It was not until both agents were used in clinical practice that reports of sepsis, tuberculosis, and infections with atypical Mycobacterium and other organisms appeared. In 2001 these observations led the US Food and Drug Administration and other regulatory bodies to modify the labeling of TNF antagonists to outline the potential risks of serious infection.

After 2001 the results of several randomized clinical trials (RCT) evaluating the safety and efficacy of TNF antagonists in RA were published. Figure 1 shows the odds ratio (OR) of serious infections for recommended doses of TNF antagonist in RA trials published between 1998 and 2007. The risk of serious infection in these trials has been relatively stable over time, with the majority of RCT having an OR of 1 for serious infection with TNF antagonist therapy.

Bongartz, et al were the first to publish a metaanalysis of the risk of serious infection with the use of TNF antagonist antibodies ${ }^{7}$. They reported an OR of 2.0 [95\% confidence interval (CI) 1.3-3.1] for serious infection using all doses of infliximab and adalimumab reported in the trials. A more recent analysis by Alonso-Ruiz, et al that included etanercept did not report a significant risk of serious infection with TNF antagonists (risk ratio $1.4 ; 95 \%$ CI $0.8-2.2$ ). A limitation of both reports was that they did not report risk of serious infection with recommended doses. To address this

See Observational studies of infections in RA: metaanalysis of TNF antagonists, page 928 


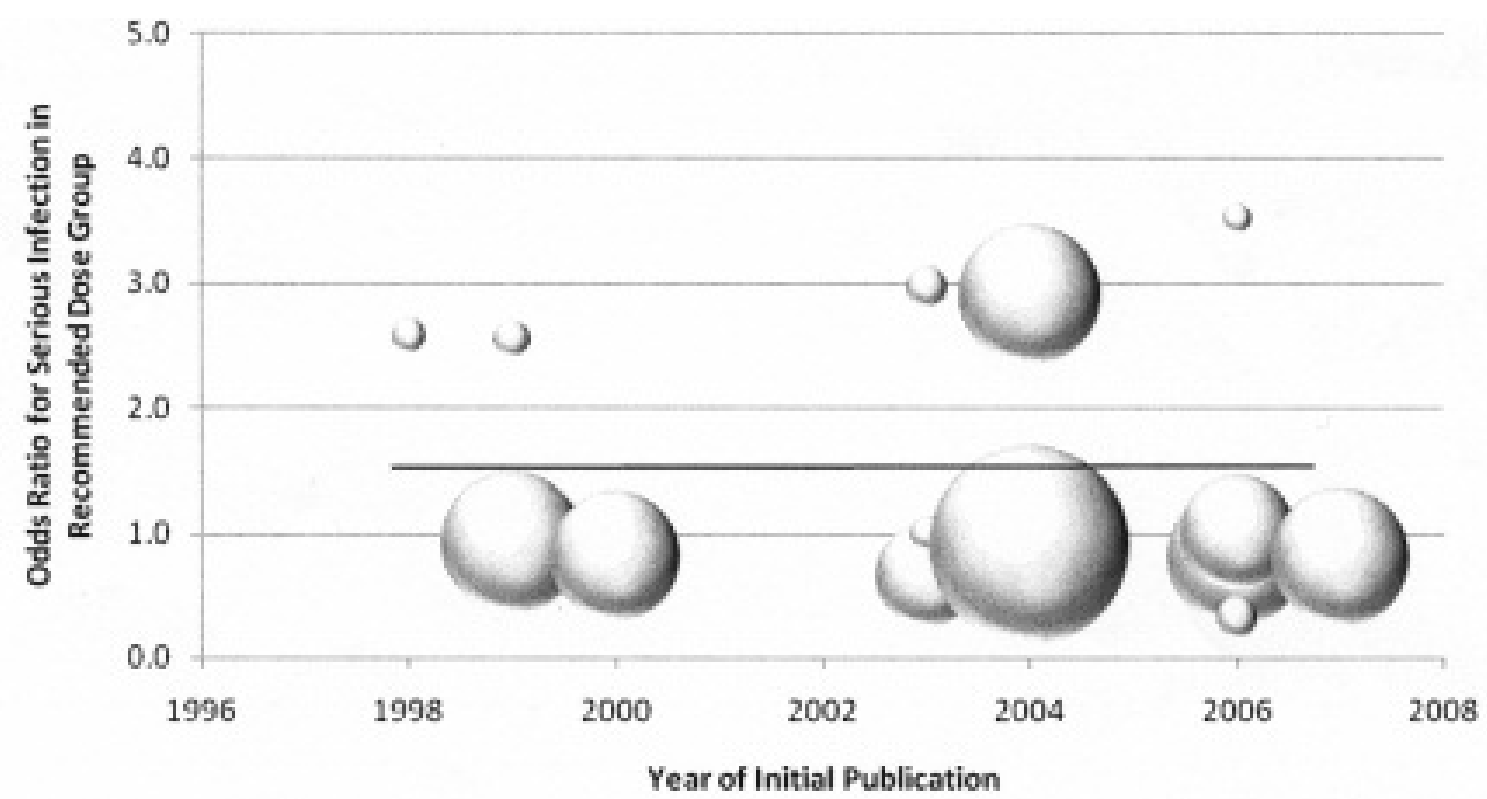

Figure 1. Odds ratio of serious infection with recommended doses of TNF antagonist versus placebo by study by year of initial publication. Each circle represents a trial, with area proportional to the inverse of the variance of the estimated treatment effect. Year of publication does not significantly affect the risk of serious infection $(\mathrm{p}=0.16)$.

limitation, Leombruno, et al performed a metaanalysis that included 16 studies with 3729 subjects receiving recommended doses of adalimumab, etanercept, or infliximab and 2618 placebo patients; an OR for serious infection of 1.21 (95\% CI 0.89-1.63) was reported ${ }^{8}$.

Published metaanalyses do not support an increased risk of serious infection with recommended doses of TNF antagonists; however, the metaanalyses agree that subjects who initiate TNF antagonist therapy at higher than recommended doses have an increased risk of serious infection. This dose-response relationship strengthens the argument that TNF antagonists may increase the risk for serious infection through a biological mechanism.

Today, many rheumatologists accept that TNF antagonists increase the risk of serious infection; however, quantifying the risk of TNF antagonist therapy is difficult, given that RA itself and the traditional medications used to treat RA may increase the risk of serious infection.

In this issue of The Journal, Bernatsky, et al describe their metaanalysis of observational studies published between 2002 and $2008^{9}$. Their analysis included 7 studies and 124,357 RA subjects receiving TNF antagonists or disease-modifying antirheumatic drugs. The rate of serious infections in their study was about 3.5 per 100 subject-years, which is strikingly similar to the rate of 3.6 per 100 subject-years noted in the RCT analyzed by Leombruno, et $a l^{8}$.

Bernatsky, et al report an increased risk of serious infection with TNF antagonist therapy (risk ratio 1.37; 95\% CI $1.18-1.60)$. The point estimate of the risk of serious infection is roughly similar to the point estimate from the RCT; however, the narrower confidence limit from the observational studies results in statistical significance. The advantages of their study are the large number of subjects, use of "real-world" TNF antagonist dosing, generalizability of results (i.e., the subjects were not highly selected as in $\mathrm{RCT}$ ), and the fact that the care subjects received was not mandated by a protocol. The limitations of their study center on the problems of observational studies and pooling them. The major limitation is that non-random allocation of subjects to treatment groups will result in confounding. Although Bernatsky, et al note that all included studies adjusted for confounders, the reality is that there are unknown and unmeasured confounders that may affect the analysis in unexpected ways.

It is not uncommon in medicine for results of observational studies to differ from RCT; often attempts to explain the differences result in new learning about the conditions, treatments, and patients being investigated. This leads to the question, why is the overall rate of serious infection similar in observational and RCT metaanalyses but the relative risk of TNF antagonist therapy different?

The relative risk of serious infection may be increased in observational studies when compared to RCT because of the difference in study populations. The mean age of subjects in the RCT was 54 years compared to 60 years in observational studies. Askling, et al estimated that relative risk of serious infection with TNF antagonist therapy increases from 1.29 to 1.75 as age increases from 54 to 60 years ${ }^{10}$. Between $12 \%$ and $17 \%$ of subjects in observational studies received a second TNF antagonist (12\%-17\%), while previous expoPersonal non-commercial use only. The Journal of Rheumatology Copyright $\subset$ 2010. All rights reserved. 
sure to a TNF antagonist was a common exclusion criterion in the early RCT. The risk of serious infection increases from $4.5 \%$ to $7.0 \%$ during treatment with a second TNF antagonist $^{10}$, and may explain the higher serious infection risk seen in observational studies.

In contrast to the above, some attributes of RCT may result in higher relative risk of serious infection compared to observational studies. The mean followup in the observational studies was over 2 years, while 10 of the 16 RCT had durations less than 6 months. Several authors have noted that risk of infection with TNF antagonist therapy is highest within the first few months of treatment, followed by decreasing risks after the first year of treatment ${ }^{10,11}$. Given the time dependency of the risk of serious infection, the shorter observation periods in RCT may result in relatively higher risks. The use of corticosteroid at baseline was similar in the RCT and observational studies; however, while it is common for observational studies to report a decrease in the corticosteroid dose ${ }^{12}$, many RCT protocols require that dose of corticosteroid remain stable throughout the study. Since corticosteroids confer a dose-dependent risk of serious infection ${ }^{13,14}$ and RCT subjects cannot reduce their corticosteroid dose, the RCT design may result in an increase in the relative risk of serious infection. Last, RCT had a much higher rate of concomitant methotrexate use. While no definitive data link methotrexate to serious infections, there has been debate in the literature. In the PREMIER trial the rate of serious infection in the adalimumab-methotrexate combination group was significantly higher than in the adalimumab monotherapy group ${ }^{15}$.

In summary, in complex ways, the differences between RCT and observational studies affect the relative risk estimates of serious infection with TNF antagonist therapy. Both types of analysis have advantages and disadvantages. Thus, clinicians need to consider all scientific approaches that help contextualize this issue.

JOHN LEOMBRUNO, BScPharm, PhD, MBA, Department of Pharmaceutical Sciences, University of Toronto, 144 College Street,

Toronto, Ontario M5S 3M2, Canada

Address correspondence to Dr. Leombruno;

E-mail: john.leombruno@utoronto.ca

\section{REFERENCES}

1. McCarthy EF. The toxins of William B. Coley and the treatment of bone and soft-tissue sarcomas. Iowa Orthop J 2006;26:154-8.

2. Carswell EA, Old LJ, Kassel RL, Green S, Fiore N, Williamson B. An endotoxin-induced serum factor that causes necrosis of tumors. Proc Natl Acad Sci USA 1975;72:3666-70.
3. Maini RN, Breedveld FC, Kalden JR, Smolen JS, Davis D, Macfarlane JD, et al. Therapeutic efficacy of multiple intravenous infusions of anti-tumor necrosis factor alpha monoclonal antibody combined with low-dose weekly methotrexate in rheumatoid arthritis. Arthritis Rheum 1998;41:1552-63.

4. Moreland LW, Baumgartner SW, Schiff MH, Tindall EA, Fleischmann RM, Weaver AL, et al. Treatment of rheumatoid arthritis with a recombinant human tumor necrosis factor receptor (p75)-Fc fusion protein. N Engl J Med 1997;337:141-7.

5. Weinblatt ME, Kremer JM, Bankhurst AD, Bulpitt KJ, Fleischmann RM, Fox RI, et al. A trial of etanercept, a recombinant tumor necrosis factor receptor:Fc fusion protein, in patients with rheumatoid arthritis receiving methotrexate. $\mathrm{N}$ Engl $\mathrm{J}$ Med 1999;340:253-9.

6. Maini R, St. Clair EW, Breedveld F, Furst D, Kalden J, Weisman $\mathrm{M}$, et al. Infliximab (chimeric anti-tumour necrosis factor alpha monoclonal antibody) versus placebo in rheumatoid arthritis patients receiving concomitant methotrexate: a randomised phase III trial. ATTRACT Study Group. Lancet 1999;354:1932-9.

7. Bongartz T, Sutton AJ, Sweeting MJ, Buchan I, Matteson EL, Montori V. Anti-TNF antibody therapy in rheumatoid arthritis and the risk of serious infections and malignancies: systematic review and meta-analysis of rare harmful effects in randomized controlled trials. JAMA 2006;295:2275-85.

8. Leombruno JP, Einarson TR, Keystone EC. The safety of anti-tumour necrosis factor treatments in rheumatoid arthritis: meta and exposure-adjusted pooled analyses of serious adverse events. Ann Rheum Dis 2009;68:1136-45.

9. Bernatsky S, Habel Y, Rahme E. Observational studies of infections in rheumatoid arthritis: a metaanalysis of tumor necrosis factor antagonists. J Rheumatol 2010;37:928-31.

10. Askling J, Fored CM, Brandt L, Baecklund E, Bertilsson L, Feltelius N, et al. Time-dependent increase in risk of hospitalisation with infection among Swedish RA patients treated with TNF antagonists. Ann Rheum Dis 2007;66:1339-44.

11. Dixon WG, Symmons DP, Lunt M, Watson KD, Hyrich KL, Silman AJ. Serious infection following anti-tumor necrosis factor alpha therapy in patients with rheumatoid arthritis: lessons from interpreting data from observational studies. Arthritis Rheum 2007;56:2896-904

12. Choquette D, Leombruno JP, Einarson TR. Effect of tumor necrosis factor antagonists on consumption of narcotic analgesics and corticosteroids over the first 12 month period in rheumatology patients. Reumatol Clin 2006;2:71.

13. Schneeweiss S, Setoguchi S, Weinblatt ME, Katz JN, Avorn J, Sax $\mathrm{PE}$, et al. Anti-tumor necrosis factor alpha therapy and the risk of serious bacterial infections in elderly patients with rheumatoid arthritis. Arthritis Rheum 2007;56:1754-64.

14. Smitten AL, Choi HK, Hochberg MC, Suissa S, Simon TA, Testa MA, et al. The risk of hospitalized infection in patients with rheumatoid arthritis. J Rheumatol 2008;35:387-93.

15. Breedveld FC, Weisman MH, Kavanaugh AF, Cohen SB, Pavelka $\mathrm{K}$, van Vollenhoven R, et al. The PREMIER study: A multicenter, randomized, double-blind clinical trial of combination therapy with adalimumab plus methotrexate versus methotrexate alone or adalimumab alone in patients with early, aggressive rheumatoid arthritis who had not had previous methotrexate treatment. Arthritis Rheum 2006;54:26-37.

J Rheumatol 2010;37:887-9; doi:10.3899/jrheum.100251 